\title{
O tornar-se adulto no imaginário coletivo de adolescentes interioranos
}

\author{
Becoming adult in provincial adolescents'collective imaginary \\ El hacerse adulto en el imaginario colectivo de jóvenes del medio rural
}

Maria Auxiliadora Motta Barreto*
Tânia Maria José Aiello-Vaisberg

\begin{abstract}
Resumo
Este trabalho é o relato de uma investigação psicanalítica do imaginário coletivo de jovens interioranos acerca da fase de vida em que se encontram e da saída da casa paterna. A pesquisa foi organizada como uma consulta terapêutica coletiva, realizada com seis jovens, com idades variando entre 15 e 21 anos, durante a qual foi usado o procedimento de desenhos-estórias com tema. A abordagem psicanalítica do material clínico permitiu a captação dos seguintes campos psicológico-vivenciais não conscientes: "fusões e confusões", "um mundo paralelo", "visão negativa do futuro" e "as escolhas". O estudo indica a necessidade de medidas psicoprofiláticas e interventivas que possam contribuir para a entrada do jovem em um processo de reapropriação de seu destino e conquista de autonomia.
\end{abstract}

Palavras-chave: adolescência; imaginário coletivo; procedimento de desenho-estória com tema; psicanálise; D. W. Winnicott.

\begin{abstract}
This paper is an account of a psychoanalytical inquiry into provincial adolescents' collective imaginary concerning their life phase and the exit from their parents' home. The research was organized as a collective therapeutic consultation with six young people, aged between fifteen and twenty-one, using the drawing-story procedure as a theme. The psychoanalytical approach of the clinical material allowed the detection of the following unconscious psychological-existential fields: "fusions and confusions", "a parallel world", "negative vision of the future" and "choices". The study indicates the necessity of psychological prevention and intervention measures that can contribute to the adolescents'
\end{abstract}

Doutora em Psicologia como Profissão e Ciência pela PUC Campinas, pró-reitora de Pesquisa, Pós-graduação e Extensão do Centro Universitário de Volta Redonda (Unifoa), professora de graduação e pós-graduação. E-mail: maria.barreto@uol. com.br.

*Professora livre-docente, orientadora do Programa de Pós-graduação da PUC Campinas. E-mail: aiello.vaisberg@gmail.com. 
entrance into a process of re-appropriation of their own destiny and autonomy.

Key-words: adolescence; collective imaginary; drawing-story procedure with a theme; psychoanalysis; D. W. Winnicott.

\section{Resumen}

El presente trabajo es el relato de una investigación psicoanalítica del imaginario colectivo de jóvenes del medio rural sobre la fase de vida en la que se encuentran y la salida del domicilio paterno. La investigación fue organizada como una consulta terapéutica colectiva, con seis jóvenes, con edades comprendidas entre los quince y veintiún años, durante la cual fue usado el procedimiento de dibujos-historias con tema. El abordaje psicoanalítico del material clínico reveló la existencia de los siguientes campos psicológicos no conscientes: "fusiones y confusiones", "un mundo paralelo", "visión negativa del futuro" y "las elecciones". El estudio indica la necesidad de prevenciones e intervenciones que puedan contribuir a la entrada del joven en un proceso de captación de su destino y conquista de autonomía.

Palabras clave: adolescencia; imaginario colectivo; procedimiento de dibujo-historia con tema; psicoanálisis; D. W. Winnicott.

\section{Introdução: o problema e o contexto}

A experiência clínica tem nos permitido entrar em contato próximo com a adolescência e suas questões, tanto por meio do atendimento de jovens quanto do atendimento de adultos (que já foram adolescentes) ou de crianças que se encaminham para sê-lo. Em particular, nos últimos anos, a clínica nos aproximou de jovens que apresentam inquietações e dificuldades em um momento especial de suas vidas: o da necessidade da saída de casa para prosseguir seus estudos em outras cidades.

Ao observar, principalmente, adolescentes que poderiam e, ou, deveriam continuar seus estudos em nível universitário, percebemos que, enquanto alguns saíam de casa para estudar e prosseguiam num desenvolvimento continuado, outros acabavam desistindo do curso, voltando para casa. Outros jovens, ainda, nem saíam, limitando seu leque de opções aos cursos que existiam em sua cidade de origem, exclusivamente pela impossibilidade de se manterem longe dos cuidados familiares, apesar de não assumirem (nem eles, nem suas famílias) essa impossibilidade. 
Além disso, ao atendermos os pais desses adolescentes no consultório, observamos que alguns temores apareciam com muita frequência: o medo de repetir os erros dos próprios pais, a preocupação de não privar os filhos do que poderiam ter e do que eles, pais, não tiveram, o receio do uso e abuso de drogas e da promiscuidade sexual, o medo de serem abandonados ou esquecidos pelo filho. Observamos que tais receios contribuíam para que adotassem condutas nem sempre facilitadoras do processo de independência dos filhos. Essas considerações, em conjunto, levaram-nos a investigar o adolescente que passa por esse momento específico por volta dos 17 anos.

É fato que são muitas as pesquisas realizadas, nos últimos anos, sobre vários aspectos relacionados à adolescência (Toneli e Vavassori, 2004; Piccinini, Ferrari, Levandowski, Lopes e Nardi, T. C. de, 2003; Ponciano e Féres-Carneiro, 2003; Camargo e Bárbara, 2004; Torossian, 2007; Mattos e Castro, 2008). No entanto, a compreensão do processo de amadurecimento em adolescentes interioranos reclamava investigações mais específicas, motivando a realização deste trabalho, que aborda a conduta como fenômeno situado na concretude do viver (Bleger, 1963/1989). Será, pois, com base em tal perspectiva que manteremos um diálogo importante com o pensamento clínico-teórico de D. W. Winnicott (1975, 1979/1983, 1993, 1999), compreendendo ampliadamente o conceito de ambiente, não apenas como condição de vida relacional e familiar, mas também para incluir a sociedade globalizada como um mundo em que vivemos. As reflexões iniciadas levaram-nos, então, a considerar que existe um complicador a mais no processo de passagem para a vida adulta, decorrente das profundas modificações sociais, econômicas, culturais e tecnológicas de nosso tempo, caracterizado pelo que se denomina Pós-modernidade (Jameson, 1991; Bauman, 1997, 2001; Harvey, 1989; Sennett, 1998). Para efeitos deste trabalho, definimos Pós-modernidade a partir da concepção de Eagleton (1996, p. 7), como:

[...] Uma linha de pensamento que questiona as noçōes clássicas de verdade, razão, identidade e objetividade, a ideia de progresso ou emancipação universal, os sistemas únicos, as grandes narrativas ou os fundamentos definitivos de explicação. [...] Vê o mundo como contingente, gratuito, diverso, instável, imprevisível, um conjunto de culturas ou interpretaçōes desunificadas gerando certo grau de ceticismo em relação à objetividade da verdade, da história e das normas, em relação às idiossincrasias e à coerência de identidades.

Nesse quadro, é possível observar, nos jovens pesquisados e seu entorno, questôes como a incerteza quanto ao futuro, que se torna maior, no momento, 
em virtude da insegurança e da instabilidade político-econômica do próprio País. Observamos, também, entre muitos adolescentes, o medo de que sua situação financeira piore no futuro, quando não dependerem mais dos pais. Além disso, vemos relacionamentos padronizados, pautados no instantâneo e no imediatismo, bem como a ansiedade decorrente da falta de laços afetivos estáveis. Entre esses fenômenos, é claramente perceptível que não só o jovem mas também sua família sofrem as consequências dramáticas do viver adolescente.

Sabemos que a família atual traz como herança uma história caracterizada por intensas alteraçôes (Ariés, 1978) de valores, de funções, em sua formação, na sua configuração e nas relaçôes entre seus membros e com a comunidade. Mesmo assim, um aspecto permanece inalterado: a importância da família no desenvolvimento psíquico de seus filhos (Gevertz, 2002). No entanto, no panorama em foco, também a família perde os parâmetros balizadores de favorecimento de condutas adequadas que promovam o amadurecimento saudável de seus filhos, tendo atitudes que impedem a saída dos filhos de casa ou dificultam sua permanência em outros locais de moradia, atraindo-o de volta. Nessas condições é que se insere o grupo de adolescentes abordado nesta investigação. $\mathrm{O}$ entorno é caracterizado por uma pequena cidade de interior, de aproximadamente 80 mil habitantes, onde existe uma prática de saída dos jovens da casa paterna para dar continuidade aos estudos. Muitos que saem têm retornado sem, ao menos, terminarem o curso de graduação que se propuseram a começar. Outros, que não saem, têm sido discriminados por continuarem em um local que não oferece muitas condições de progresso acadêmico ou profissional.

\section{Estratégias teórico-metodológicas ${ }^{1}$}

Para realizarmos a pesquisa, optamos por uma abordagem que viabilizasse a apreensão dos diferentes significados de uma experiência específica, além de permitir uma compreensão mais profunda do caráter complexo e multidimensional dos fenômenos, em sua manifestação natural. Em nosso caso, circunscreve-se a um âmbito coletivo (jovens interioranos), o que nos conduz ao contato com o imaginário social. Assim, nossa opção metodológica baseou-se numa antropologia que considera que o fenômeno humano apresenta especificidades que abordagens objetivantes não são capazes de abranger, requerendo uma perspectiva epistemológica sui generis.

\footnotetext{
Os procedimentos usados foram devidamente aprovados pelo CEP (Conselho de Ética e Pesquisa) da PUC Campinas. O encontro com os adolescentes foi autorizado por um termo de consentimento livre e esclarecido, assinado pelos adolescentes e por seus responsáveis, quando menores de 18 anos.
} 
Consideramos o imaginário social como manifestações simbólicas de subjetividades coletivas, emergentes de um campo subjacente de natureza psicológica inconsciente. Ressaltamos, então, que a teoria que norteia tal consideração é a Psicanálise, considerada por Bleger (1963/1989) com base em uma perspectiva dialética.

Atuamos desprovidas de respostas e cuidando para que qualquer conhecimento anterior não se apresentasse como o principal da pesquisa. Procuramos, dessa forma, fazer uso do método não apenas como um conjunto de recomendações de bem fazer e sim como um fazer que se baseia numa atitude, que é fenomenológica, porque prega o desapego às crenças e teorias e o cultivo da máxima abertura para o acontecer clínico. Assim, configuramos nossa pesquisa como um processo de investigação psicanalítica, que abandona a divisão positivista sujeito-objeto e propõe um encontro inter-humano, tendo por expectativa a expressão do indivíduo. Fizemos uso de associações livres e da atenção flutuante como condições de investigação, transpondo-as do dispositivo-padrão para a pesquisa, com os ajustes devidos. Silva (1993, p. 20) destaca com clareza esse procedimento quando coloca que o método em psicanálise caracteriza-se

[...] por uma espécie de jogo em que fantasias de ambos os interlocutores organizam-se em busca de um consenso sempre questionado a respeito do avesso do que foi dito. Ou seja, o método da psicanálise caracteriza-se por abertura, construção e participação.

Quando nos referimos a campo psicológico não consciente, reportamonos a Bleger (1963/1989, p. 37), para quem campo é "o conjunto de elementos coexistentes e interatuantes em um dado momento", de onde emergem as condutas. O campo psicológico está implicado nas três áreas de expressão da conduta: a área mental, a corporal e a da atuação no mundo externo, diferenciação feita apenas para atender às necessidades de estudo e intervenção, uma vez que se trata de um fenômeno essencialmente unitário. Realizada desde a atenção flutuante, a captação dos campos psicológico-vivenciais não conscientes se faz pela apreensão de experiências únicas daquele indivíduo em particular que, no entanto, são características do humano e estão, muitas vezes, encobertas por estratégias defensivas (Ferreira, 2006). Participaram da pesquisa adolescentes para os quais está colocada concretamente a alternativa de sair de casa, por morarem em cidade do interior do Estado de São Paulo, onde não há cursos de graduação suficientes, em quantidade, variedade e qualidade, para atenderem à demanda. Considerando que, em nossa sociedade, o 
jovem interiorano deixa a casa dos pais, se o faz, por volta dos 17 anos, fizemos um recorte em termos etários na faixa entre 15 e 21 anos, por nos interessar, em particular, o adolescente que está em vias de sair de casa para estudar.

Assim, foram contatados estudantes do ensino médio e curso prévestibular, de classe média, em função dos objetivos da investigação. No entanto, consideramos tal critério exclusivamente no sentido de tais jovens pertencerem a famílias que, de antemão, incentivam e apoiam o ingresso em curso de graduação.

Privilegiando uma metodologia clínica que busca examinar qualitativa e detidamente um fenômeno, optamos por realizar um estudo baseado em um acontecer grupal, similarmente a pesquisas anteriores que usaram essa metodologia (Aiello-Vaisberg, 1999). Empregamos a definição de grupo proposta por Bleger de que

Um grupo é um conjunto de pessoas que entram em interação entre si, porém, além disso, o grupo é, fundamentalmente, uma sociabilidade estabelecida sobre um fundo de indiferenciação ou de sincretismo, no qual os indivíduos não têm existência como tais e entre eles atua um transitivismo permanente (Bleger, 1980/1998, p. 104).

Nessas condiçôes, inclusive o pesquisador está envolvido em tal sincretismo, o que afeta tanto a realização do próprio encontro como a elaboração da narrativa feita após este. Opera-se, pois, em um campo inter-humano, que assim se configura, e no qual estão presentes inteiramente todos os participantes.

Paralelamente, havíamos optado por realizar uma Consulta Terapêutica Coletiva (CTC) que se constitui como um enquadre clínico diferenciado que prioriza o acontecer clínico desde o encontro inter-humano. Esse recurso permite a abordagem do imaginário coletivo, em registro psicoprofilático ou psicoterapêutico, em conformidade com o método psicanalítico (AielloVaisberg, 2005). Na CTC, propõem-se atividades com potencial expressivo, favorecendo um diálogo estabelecido com base em palavras ou gestos que emergem da imaginação simbólica.

Escolhemos, como mediador dialógico, o procedimento dedesenhos-estórias com tema, desenvolvido por Aiello-Vaisberg (1999) com base na concepção original de Trinca (1976). Esse procedimento é concebido como "[...] uma das modalidades práticas através das quais o método psicanalítico pode ser concretizado [...]" (Aiello-Vaisberg, 1999). Consideramos que, focalizando 
uma experiência a qual, conforme nossa observação na clínica, nem sempre é agradável, esperada ou desejada pelo jovem (como tornar-se adulto, ou sair da casa paterna), era preciso certo cuidado na forma de abordar o assunto, já que se tratava de um campo temático que poderia estimular condutas defensivas diversas, como negação, fuga, racionalização. Usamos, assim, o recurso mediador (desenho-estória com tema) para facilitar a expressão sem provocar reaçôes dissociadas em que pudessem prevalecer aspectos cognitivos, isolados do sentir e do viver. Nossa intenção, então, foi conseguir expressões subjetivas que, por sua vez, permitissem o acesso a determinantes inconscientes.

Foram convidados a participar jovens com os quais uma das pesquisadoras já havia tido algum contato e, por isso, já se soubesse que faziam parte da população a ser investigada, mas o convite não foi limitado a eles. Também foram obtidas indicações diversas pelo processo de "snow ball sampling" que, segundo Berthoud (2003, p. 80), "consiste em indicações progressivas de pessoas que conhecem e queiram indicar e, ou, convidar outras pessoas que se encaixem nos critérios estabelecidos".

Tendo realizado o encontro com os jovens, iniciamos as narrativas. Consideramos o acontecer clínico como origem da primeira narrativa, que, longe de ser um retrato fiel do encontro, é a revelação dos significados primeiros. A partir dela, outras narrativas foram feitas, utilizando-se dos processos de associação livre e atenção flutuante, pela pesquisadora presente na CTC, modificada pelo próprio encontro e pela própria narrativa. Lembramos que se trata de um procedimento que permite e prioriza o engajamento inteiro dos envolvidos, um encontro inter-humano em que os significados não são isolados de uma prática profissional clínica, nem da vivência de pessoas que passam ou passaram pelo fenômeno pesquisado. Nesta concepção, diferente de um relatório de dados, a narrativa em si constitui uma experiência (AielloVaisberg e Machado, 2005). Em continuidade, as primeiras narrativas e desenhos-estórias foram trabalhados no âmbito do coletivo de pesquisa em que este trabalho foi desenvolvido (Grupo de Pesquisa CNPq - PUC Campinas Atenção Psicológica Clínica em Instituições: Prevenção e Intervenção).

O desapego a modelos teóricos anteriores, aos quais se tende a encaixar ou comparar experiências, foi cultivado ao longo de todo o trabalho. No entanto, é preciso esclarecer que se levando em conta a impossibilidade concreta de tal ideal, já que nossa formação é na Psicologia e na psicanálise, procuramos ter o cuidado de manter tais conhecimentos e teorias apenas como fundo. Ressaltamos que nos interessavam, desde o primeiro momento, os traços ligados à "terceira área" - o espaço potencial existente entre o indivíduo e o meio, entre o mundo interno e externo, em que o indivíduo "experimenta 
o viver criativo" (Winnicott, 1967a/1975) - e não os ligados ao campo da consciência, do qual fazem parte os conhecimentos teóricos.

Trabalhamos, então, com o campo intersubjetivo, tanto no encontro com os adolescentes quanto nas reuniōes com o grupo de pesquisa, configuradas como um encontro especializado imbuído permanentemente de intenção investigativa, considerando todos os aspectos explícitos e não conscientes presentes. Nesse tipo de encontro, o encaminhamento também é diferenciado, pois não prevê apenas uma análise solitária do pesquisador sobre um material coletado. Existe um compartilhar de conhecimentos e de imagens com o coletivo de pesquisa que amplia a compreensão do fenômeno.

\section{Apresentação do acontecer clínico e o imaginário encontrado}

Foi feito um contato telefônico com os adolescentes para informação da pesquisa e convite para participação, e foi solicitado, também, que indicassem outra pessoa, com idade aproximada à sua, para ser contatada. Agendouse o encontro em grupo, que aconteceu no consultório psicológico, local escolhido pelo fato de se tratar de uma consulta e atender às exigências de acomodação e localização. Constelado um enquadre de encontro grupal, em termos de uma CTC (Aiello-Vaisberg, 2005) com os seis jovens que atenderam ao convite, solicitamos que cada um desenhasse um adolescente entre 15 e 21 anos e que, terminado o desenho, inventasse uma estória sobre a figura desenhada, escrevendo-a no verso da folha. Não deveriam identificar-se, mas apenas colocar sua idade e sexo.

Quando terminaram os desenhos-estórias, abrimos um espaço intermediário de palavra (Sirota, 1998), um diálogo sobre o que acharam da experiência e o que pensavam sobre a adolescência. Tanto o uso do procedimento como a conversa grupal foram instaurados com o objetivo de favorecer um movimento integrador no sentido da possibilidade de um surpreender-se por si mesmo, o que pode ter um efeito transformador.

No encontro, os jovens acolheram muito bem a proposta e imediatamente se dispuseram a realizar o solicitado. Não se mostraram resistentes a desenhar, tampouco a falar ao final, sobre a experiência vivenciada, o que levou, aproximadamente, duas horas e meia.

Para que o leitor possa acompanhar parte do caminho que fizemos nesta investigação, colocamos, em anexo, os desenhos elaborados pelos jovens (figura 1). 
Figura 1 - Desenhos produzidos pelos adolescentes que participaram da pesquisa.
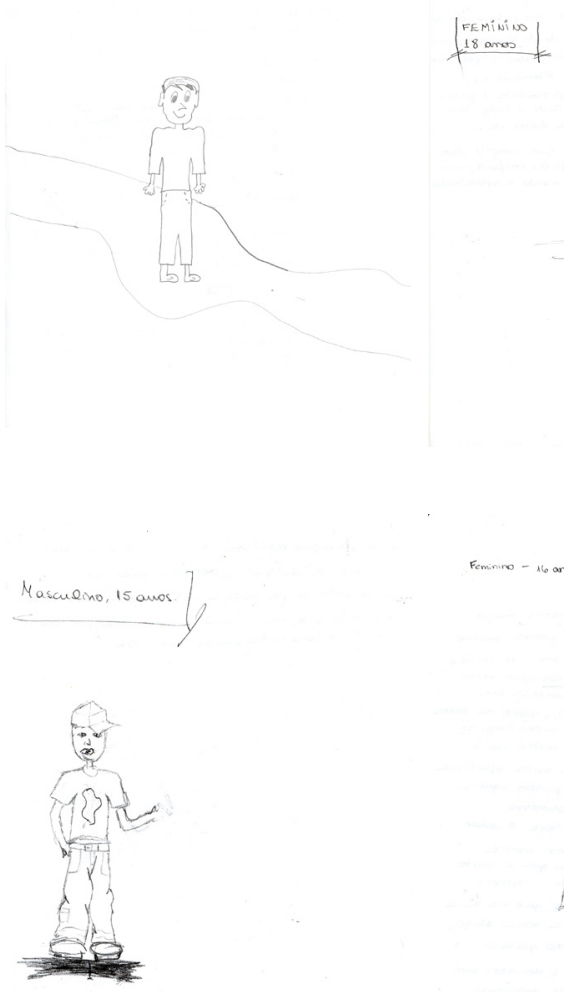
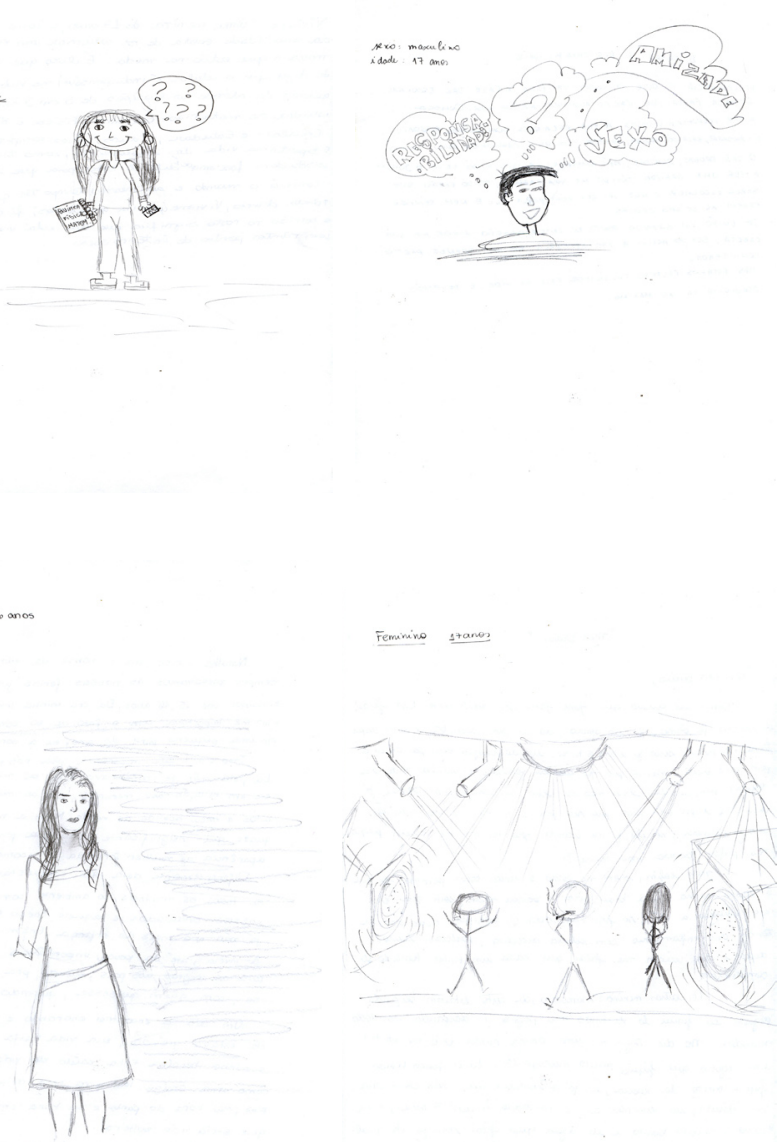

O diálogo empreendido após os desenhos-estórias envolveu desde o achar "engraçado" desenhar um adolescente, "porque todos são muito diferentes", passou pela dificuldade de escolher o que colocar no desenho, pela família que faz parte da adolescência, pelas dúvidas que surgem nessa idade, pelo que apareceu nos desenhos-estórias (sexo, drogas, baladas, telefones, livros, dúvidas, sentimento de solidão), até os medos quanto ao futuro e a provável saída de casa.

Terminado o encontro fizemos uma primeira narrativa que serviu como um organizador das ideias e vivências que surgiram durante a CTC e na análise do material coletado. Após essa narrativa, fizemos encontros com o grupo de 
pesquisa que também auxiliaram na detecção dos campos psicológicos não conscientes, considerando que esse grupo tem a mesma formação teóricoclínica das pesquisadoras. Dessa forma, cada desenho-estória foi considerado individualmente e em grupo, pela pesquisadora e pelo grupo de pesquisas, num movimento de captação do que estava sendo desvelado pelos jovens e não com a preocupação de identificar categorias pré-estabelecidas. Encontramos, com base nos desenhos-estórias dos adolescentes que participaram da pesquisa e das reflexôes/considerações feitas após o encontro, quatro campos psicológicos não conscientes: "fusões e confusōes", "um mundo paralelo", "visão negativa do futuro" e "as escolhas", que apresentamos a seguir.

Nomeamos "Fusões e confusões" o campo delineado por experiências emocionais fusionadas e confusas dos adolescentes, em uma associação à noção de indiferenciação inicial entre mãe e bebê (Winnicott, 1987/2002). Referimo-nos, aqui, às misturas enfrentadas pelos jovens, demonstradas pela relevância que o outro tem para eles nos desenhos-estórias, senão direta, indiretamente, e que se mistura à própria condição de ser do adolescente. Embora a relevância do outro seja característica do humano, e não só da adolescência, ganha importância como parte de um campo não consciente pela frequência e pela diversidade com que aparece. Muitas vezes é o outro que passa a ser a referência para o adolescente, que se desconsidera a si mesmo, quase se anulando. Referimo-nos a confusóes quando se impóe a presença de contrastes, caracterizada pela marcação da diferença e da oposição entre infância e vida adulta, entre prazer e dever, entre certo e errado. É presente a confusão de sentimentos, quando, por exemplo, da ansiedade pela saída de casa, contraposta à insegurança com a prevista independência familiar. Confusão de posicionamento, quando ora se portam como adultos independentes e responsáveis, ora se portam como completamente dependentes da opinião dos pais. Confusão de percepção, ora antevendo um futuro de realizaçóes, ora se preparando para a "pior fase da vida", extremamente conturbada. Os conflitos advindos dessas diferenças e dicotomias muitas vezes culminam na confusão entre atividade e passividade, num movimento em que deixam de praticar ações que conduzem a um crescimento saudável (autonomia, com reaçôes de resposta cega à expectativa do grupo) dependência.

Foi nomeado "Um mundo paralelo" o campo que se refere ao fato da adolescência aparecer de forma concreta, como um lugar. Sendo um lugar onde se vive, passa a ter as mesmas características do que é descrito por Winnicott (1971/1975) em "O lugar em que vivemos", ao se referir à terceira área, e traz o imaginário como ambiente. Nele ainda existe uma proteção familiar natural à qual se está acostumado, como muitos jovens se reportaram. Desse lugar, é 
permitido observar o que acontece e vivenciar experiências, imaginando-se a salvo e ensaiar os passos para a vida adulta.

Ao mesmo tempo, esse mundo paralelo constitui um lugar para o não acontecer. Nele o mundo está como que suspenso, apesar da intensidade das vivências, e a fantasia apresenta-se como defesa e proteção. "A fantasia é parte do esforço feito pelo indivíduo para lidar com a realidade interna. Pode-se dizer que a fantasia e o devaneio são manipulaçóes onipotentes da realidade externa" (Winnicott, 1935/1982, p. 248)2.

Por trás desse não acontecer, a criação de um mundo paralelo permite o vivenciar dos riscos e perigos que envolvem a adolescência, como descreve um dos jovens na sua estória:

A vida dele era só "curtissão" (sic), não queria saber de estudo, não dava a mínima pra nada, a não ser para suas saídas. Ele pensava estar certo, em relação a suas atitudes, e com isso não percebia que estava estragando sua vida.

Ou ainda outra adolescente, que descreve as tais baladas, tão frequentadas pelos jovens, onde a presença de álcool e drogas é uma constante. Essas baladas, que representam um momento de saída da realidade, são retratadas como algo mágico, como uma droga, que antecede um futuro que não é visto de maneira muito otimista.

Não pretendendo um aprofundamento sobre as causas e outras questôes que permeiam o frequente uso e abuso de drogas entre os adolescentes, que pela própria fase vital encontram-se mais vulneráveis a sofrimentos emocionais (Bergeret, 1974/2000; Winnicott, 1967b/1999, 1968a/1975, 1968b/1999), pontuamos que esse tema também esteve presente nos desenhos-estórias dos jovens pesquisados, de forma mais ou menos direta. Assunto bastante explorado nas últimas décadas (Souza, Martins, 1998; Avi, Santos, 2000; Baús, Kupek, Pires, 2002; Flisher et al., 2003; Guimarães et al., 2004; entre outros), o uso de drogas na adolescência continua sendo comprovado como um fenômeno que envolve diversos fatores individuais e sociais.

Nos desenhos-estórias em que aparece a referência a drogas de forma explícita, pode ser constatada a imagem de destruição, de malefício, de risco, mas, ao mesmo tempo, de algo quase natural, que faz parte do cotidiano.

\footnotetext{
Winnicott (1935/1982) ainda coloca como características da defesa maníaca algumas que constatamos estar presentes nos jovens: negação da realidade interna, fuga da realidade interna para a externa, manutenção das pessoas da realidade interna em "animação suspensa", negação de sensações de depressão através de sensações opostas, entre outras.
} 
Entre as considerações possíveis acerca do uso de drogas na adolescência, destacam-se aspectos sociais, como estímulo e apoio, por parte dos adultos, ao uso de drogas lícitas como álcool e tabaco, o que inclui a facilidade de acesso do jovem às drogas em reunióes sociais diversas, inclusive dentro de suas casas, e a experimentação encarada como um rito de iniciação em que não beber ou não fumar significa infantilidade, além da desestruturação e, ou, a falta de apoio familiar. Percebe-se, também, que, no geral, a banalização do tratamento dado à questão das drogas, inclusive pela divulgação feita pela mídia que ainda anuncia propagandas de bebidas alcoólicas, cigarros e festas livres, muitas vezes, promove o desenvolvimento de hábitos que favorecem a exposição a situações que facilitam o uso problemático de drogas. Apesar de ser evidente que tal uso se sustenta por motivos particulares e diversos, essas situações expõe a diversos riscos que poderiam ser evitados.

Também como parte de um mundo paralelo, aparece a forma como a sexualidade é vivenciada entre os adolescentes. Sofrendo influência direta e sendo moldada pela cultura na qual o indivíduo está inserido, a expressão da sexualidade torna-se um reflexo do tempo e dos costumes de uma época. Assim, na adolescência em particular, em função das novas exigências decorrentes das transformações físicas e das vivências emocionais, a sexualidade adquire grande complexidade; por um lado, sendo reprimida pela tradição socialreligiosa do País; por outro, sendo excessivamente estimulada, inclusive pela mídia (Outeiral, 2003). A esse respeito, basta ligar a televisão em qualquer canal da tevê aberta, principalmente nos horários das telenovelas, em que crianças e jovens estão em suas casas, que as cenas eróticas, quando não de sexo explícito, aparecem com frequência notável.

No grupo de jovens pesquisado, a sexualidade aparece referenciada nos desenhos-estórias, assumindo diversas manifestações. Ora é negada com desenhos de corpos muito infantis, ora é acentuada com desenhos sexualizados, mas não vulgarizados. Aparece explicitamente na conversa sobre a preferência por determinado tipo de parceiro, mas aparece também de forma dúbia, nos desenhos em que não há a presença de um corpo, mas a palavra sexo é escrita e colocada no nível das ideias. Aparece ora carregada de consequências dramáticas, como uma gravidez indesejada, ora com a naturalidade comum ao grupo, referindo-se aos "ficantes".

Essas aparições variadas fazem pensar em como os jovens ainda não integram a sexualidade na própria personalidade e respondem às demandas socioculturais, muitas vezes, sem estarem preparados emocionalmente para tal. Vivenciada como não integrada, a sexualidade adquire um caráter estranho ao próprio corpo e pode trazer, como reflexo, um pseudo-sentido para sua 
vivência ${ }^{3}$. Em vez de significar uma expressão de desenvolvimento saudável vinculada a valores mais amplos como a afetividade e outros mais específicos da sociedade em que vivem, passa a significar um fim em si, ou, ainda pior, passa a não significar.

"Visão negativa do futuro" refere-se ao campo vivencial segundo o qual a vida adulta é percebida como fundamentalmente problemática e frustrante. Esse campo surge da reflexão sobre a diferença na forma de encarar o futuro, revelada pelos jovens pesquisados. Diferentemente de alguns anos atrás, em que os jovens ansiavam por atingir a maioridade na expectativa de um futuro promissor, atualmente é comum adolescentes não verem pela frente um futuro animador: "O jovem garoto percebia que a sua vida de prazeres e mordomia estava cada vez mais perto do fim".

O futuro é definido como sinônimo de não ser cuidado e sim cuidar, de ter que sustentar uma família, de não ter tempo para os filhos de tanto trabalhar, de não fazer o que gosta para fazer o que dá dinheiro e vice-versa, e temem, na adolescência, fracassar: não passar no vestibular, e decepcionar os pais.

Essa perspectiva parece produzir um movimento de atração ao núcleo familiar que impede ou dificulta os "ensaios" de afastamento necessários ao estabelecimento de um desenvolvimento saudável.

Lembrando os estágios apontados por Winnicott (1941/1982) no Jogo da Espátula, é possível compará-los à adolescência. No último estágio do jogo, desenvolve-se a capacidade da criança de brincar sozinha, supondo que a mãe esteja, ali, disponível e, finalmente, cria-se o espaço em que se torna possível a brincadeira conjunta em que tanto mãe quanto filho, separados, introduzem suas brincadeiras. Em similaridade, a adolescência pode ser comparada a esse terceiro estágio, o de treinar a largar a espátula, representada, nesse caso, pela casa paterna, confiando que pode deixá-la para trás, sem se sentir desesperado ${ }^{4}$ com a perda da mãe interna. No entanto, quando os próprios pais não acreditam no gesto espontâneo e na capacidade criadora de seus filhos, anteveem perigos e não possibilidades de realização.

Não tendo grandes vantagens em se tornar adulto, o jovem pode ter embotada sua aspiração por se sentir vivo e real, e o movimento natural que

Como toda área do viver, a sexualidade pode ser experimentada de forma integrada, como real experiência lúdica e criativa no encontro entre duas singularidades, ou dissociada, em função da ação do falso self - sentimento de ausência de si. Pode ainda ser sentida como de invasão do si-mesmo, em direção ao abismo das agonias (Machado; Aiello-Vaisberg, 2004).

4 Isso remete ao conceito de agonia impensável de Winnicott (1962a/1983, 1968c/1994) que se refere à sensação de intrusão sentida pelo bebê como ameaça de aniquilamento. Tal sensação é decorrente da falha do ambiente sustentador e leva a uma interrupção do processo de continuidade da própria existência do bebê. Já vimos que a integração depende da provisão ambiental de segurança e fornece o sentido de unidade ao indivíduo. 
inclui o fluir de si como criança, como adolescente, como adulto, como idoso, fica comprometido e freia a tendência de realização de seu potencial humano.

Em continuidade à designação dos outros campos, "As escolhas" foi o nome aposto ao campo desvelado pelos desenhos-estórias feitos com pontos de interrogação, com pés apontando para direções opostas, com cabeça sem corpo, com corpo sem mãos e pés, com caminhos ora estreitos, ora largos, sinuosos, com pessoas sem rosto, presentes em todos os desenhos.

Está ligado à questão da decisão, anterior ao ato da escolha, mas esta foi considerada como campo não consciente porque é sua necessidade que desperta o aparecimento da dúvida. Partimos da ideia de que as grandes dificuldades em escolher são decorrentes das dúvidas e incertezas, e que estas podem ser normais ou patológicas.

Uma dúvida pode ser considerada saudável quando envolve alternativas analisadas com vantagens e desvantagens. Pode ser patológica, quando carregada de ansiedade excessiva que paralisa o indivíduo e impede suas escolhas 5 . Pode ser patológica, também, quando é feita tendo por base o falso self, não integrando desejos encarados como opostos, não considerando as necessidades e características de quem escolhe. A exemplo disso, um desenhoestória em que o jovem escreve sobre a "curtissão" (sic) de suas saídas como algo que "estraga" sua vida, retrata claramente a questão da oposição entre o que considera prazeroso contraposto ao que considera como certo, denunciando falta de confiança em si por "não perceber" que está estragando sua vida. É possível desvelar a sensação de despreparo para a entrada na vida adulta, onde os próprios desejos, intensos, aparecem como pouco importantes, mas não surgem outros que sejam mais compensadores.

Adotada como referência para as próprias escolhas, a avaliação dos outros implica na adoção de diferentes formas de agir e, muitas vezes, expõe o jovem a situaçôes para as quais não se encontra preparado ou, em outro extremo, impede-o de se afastar da família. Nessas condiçōes, o próprio adolescente pode justificar obstáculos reais para esse afastamento, como alegar falta de recursos financeiros, mas pode, também, agir de forma a não cumprir a possibilidade de sair.

O despreparo para a entrada na vida adulta conduz a outra questão: a de que as escolhas são facilitadas pelo sentido que adquirem para quem escolhe

\footnotetext{
Não é pretensão desta pesquisa esgotar os motivos que conduzem a uma escolha que possa ser considerada patológica, mas abordar os aspectos que surgiram do material coletado.
} 
e sendo o sentido algo que não se constrói sozinho ${ }^{6}$, e sim na coexistência (Bleger, 1963/1989), revela-se a impotência intergeracional que se reflete nesse preparo, ou despreparo, dos jovens para o mundo adulto.

\section{Considerações finais}

Tendo como objetivo inicial investigar o imaginário de adolescentes interioranos sobre o momento particular de saída da casa paterna, enquanto fato representativo do ingresso no mundo adulto, pudemos perceber que, de acordo com os campos psicológicos desvelados, muitas vezes, esses jovens retornam e, ou, se cristalizam numa atitude passiva (campo imaginário "Fusões e confusóes"), encarando o futuro como uma loteria (campo imaginário "Visão negativa do futuro"), refugiando-se e se entregando a uma adolescência muitas vezes prolongada (campo imaginário "Um mundo paralelo"), o que é favorecido pela atitude familiar e social de não o preparar para a entrada no mundo adulto e para as escolhas que deverá fazer (campo imaginário "As escolhas").

Numa consideração sobre as idiossincrasias da sociedade atual, em que não há referências e motivações que forneçam um equilíbrio, muitas vezes, deparamos o relato de uma condição existencial sem sentido. Nessas condições, a entrada na vida adulta ficou nebulosa, pouco definida, sem contornos.

Assim, é possível observar que, permeando os campos desvelados, encontra-se sempre, como pano de fundo, a insegurança concreta da vida cotidiana. Nossos jovens são criados, atualmente, de forma diferente do modo mais tradicional, que já dava responsabilidades paulatinamente. A prática atual de privar a criança e o adolescente de composiçôes com a realidade que permitam agir espontânea e criativamente diante de situaçôes diversas com responsabilidade parece realmente estabelecer uma divisão drástica entre mundo infantil e adulto, contribuindo para o medo do futuro e para a dificuldade do estabelecimento de metas.

$\mathrm{O}$ quadro que se apresenta denuncia, frequentemente, a dúvida como resultado do não poder confiar em suas próprias capacidades nem nas capacidades decisórias dos pais que, sofrendo a influência das condições sociais, também deixaram cair por terra muitas das certezas que tinham.

Na verdade, o mundo contemporâneo é todo cheio de dúvidas: as grandes narrativas totalizadoras, religiosas ou políticas, perderam força nas últimas décadas e os indivíduos não contam, em nenhuma área, com prescrições bem

6 Essa também é uma das justificativas para a elaboração desta tese em conjunto com os adolescentes e o grupo de pesquisas. 
definidas acerca do que é melhor: adaptar-se ao modus vivendi estabelecido, transformá-lo (lembrando que, para se ver como agente de mudança, é preciso nutrir esperança de transformação da realidade) ou propor novos projetos para o mundo.

Baseadas nos campos encontrados, percebemos um panorama geral em que as perspectivas futuras tornam-se sombrias. Deixam de ser uma real possibilidade de concretização de um percurso humano determinado sóciohistoricamente, no entanto único, já que individualizado e autônomo e se insere como uma possibilidade irreal. Irreal no sentido de falsa, já que, muitas vezes, engana-se quem assume este ou aquele caminho (ficar ou sair da cidade natal), ao ter a sensação de que foi o agente da escolha, quando, na verdade, foi escolhido pelo sistema. Nos moldes blegerianos, sendo todos produtores, mas também produtos da vida social, muitas vezes, nós nos iludimos com uma suposta liberdade para as escolhas que fazemos, o que impede a espontaneidade. Pensando a espontaneidade como algo que não se faz abstraidamente das condições concretas de vida, concordamos com Winnicott quando aponta a importância da escolha não submissa, da escolha que se faz a partir do ser, da escolha de um fazer que seja "ser e fazer", isto é, que se funde no estilo de cada um.

Pensando psicoprofilaticamente, considerando o adolescente um ser criativo que tende naturalmente à realização das próprias potencialidades, desde que disponibilizado um ambiente facilitador, é interessante e necessária a tentativa de reabilitação do jovem na reapropriação de seu destino, que estará tanto mais saudável quanto mais sentir-se vivo, real e capaz de uma escolha do próprio caminho configurada pela gestualidade espontânea e transformadora do próprio mundo.

\section{Referências}

Aiello-Vaisberg, T. M. J. (1999). Encontro com a loucura: transicionalidade e ensino de psicopatologia. 185f. Tese de livre-docência, Instituto de Psicologia, Universidade de São Paulo.

Aiello-Vaisberg, T. M. J. (2005). Consultas terapêuticas coletivas e abordagem psicanalítica do imaginário social. In: Vaisberg, T. M. J.; Ambrósio, F. F. (org.). Caderno Ser e Fazer: Reflexões Éticas na Clínica Contemporânea. (pp. 27-44). São Paulo: Instituto de Psicologia da Universidade de São Paulo. 
Aiello-Vaisberg, T. M. J. \& Machado, M. C. L. (2005). Narrativas: o gesto do sonhador brincante. In: IV Encontro Latino Americano dos Estados Gerais da Psicanálise, São Paulo. Trabalhos do IV Encontro Latino Americano dos Estados Gerais da Psicanálise. São Paulo: Estados Gerais da Psicanálise.

Ariés, P. (1978). História social da criança e da família. Rio de Janeiro: Zahar.

Avi, M. C.; Santos, M. A. Percepção do relacionamento familiar em mães de adolescentes usuários de drogas. In: Luis, M. A. V.; Santos, M. A. (org.). Uso e abuso de álcool e drogas. (pp. 115-125). Ribeirão Preto: Legis Summa.

Barreto, M. A. M. (2006). Do voo preciso: considerando o imaginário coletivo de adolescentes. Tese de Doutorado em Psicologia como Profissão e Ciência, Pontifícia Universidade Católica de Campinas.

Bauman, Z. (1997). O mal-estar da Pós-modernidade. Rio de Janeiro: Jorge Zahar.

Baus, J.; Kupek, E.; Pires, M. (2002). Prevalência e fatores de risco relacionados ao uso de drogas entre escolares. Revista de Saúde Pública, São Paulo, 36 (1), $40-46$.

Bergeret, J. (1974). Personnalité normale et pathologique. Paris: Dunod, 2000.

Berthoud, C. M. E. (2003). Ressignificando a parentalidade: os desafios de ser pais na atualidade. Taubaté: Cabral.

Bleger, J. (1963). A psicologia da conduta. (2. ed.). Porto Alegre: Artes Médicas.

Bleger, J. (1980). Temas de Psicologia: entrevista e grupos. (2. ed.). São Paulo: Martins Fontes, 1998.

Camargo, B. V. \& Bárbara, A. (2004). Efeitos de panfletos informativos sobre aids em adolescentes. Psicologia: Teoria e Pesquisa, 20 (3), 279-287.

Eagleton, T. (1996). As ilusões do pós-modernismo. Rio de Janeiro: Jorge Zahar.

Ferreira, M. C. (2006). Encontrando a criança adotiva: um passeio pelo imaginário coletivo de professores à luz da psicanálise. Tese de Doutorado 
em Psicologia como Profissão e Ciência, Programa de Pós-graduação em Psicologia do Centro de Ciências da Vida, Pontifícia Universidade Católica de Campinas.

Gevertz, S. (2002). Um olhar psicanalítico à sociedade contemporânea. Revista Brasileira de Psicanálise, São Paulo, 36 (2), 263-276.

Guimarães, J. L. et al. (2004). Consumo de drogas psicoativas por adolescentes escolares de Assis, SP. Revista de Saúde Pública, São Paulo, 38 (1), 130-132.

Harvey, D. (1989). Condição Pós-moderna. São Paulo: Loyola.

Jameson, F. (1991). Pós-modernismo: a lógica cultural do capitalismo tardio. São Paulo: Ática.

Flisher, A. J. et al. (2003). Substance use by adolescents in Cape Town: prevalence and correlates. Journal of Adolescent Health, San Francisco, 90, $65-72$.

Mattos, A. R. \& Castro, L. R. (2008). Ser livre para consumir ou consumir para ser livre?. Psicologia em Revista. 14 (1), 151-170.

Outeiral, J. (2003) Adolescer: estudos revisados sobre adolescência. (2. ed.). Rio de Janeiro: Revinter.

Piccinini, C. A.; Ferrari, A. G.; Levandowski, D. C.; Lopes, R. S. \& Nardi, T. C. de. (2003). O bebê imaginário e as expectativas quanto ao futuro do filho em gestantes adolescentes e adultas. Interaçôes. 8 (16), 81-108, jul-dez.

Ponciano, E. L. T. \& Féres-Carneiro, T. (2003). Modelos de família e intervenção terapêutica. Interações. 8 (16), 57-80, jul-dez.

Silva, M. E. L. (1993). Pensar em psicanálise. In: Silva, M. E. L. (org.). Investigação e Psicanálise. (pp. 11-25). Campinas: Papirus.

Sennett, R. (1998). A corrosão do caráter: consequências pessoais do trabalho no novo capitalismo. Rio de Janeiro: Record.

Sirota, A. (1998). Des espaces culturels intermédiaires. In: J. Barus-Michel e F. Giust-Desprairies. La scène sociale: crise, mutation, émergence. Paris: Eska.

Souza, D. P.; Martins, D. T. (1998). O perfil epidemiológico do uso de drogas entre estudantes de $1^{\circ}$ e $2^{\circ}$ graus da rede estadual de ensino de Cuiabá, Brasil. Cadernos de Saúde Pública, Rio de Janeiro, 14 (2), 391-400. 
Toneli, M. J. F. \& Vavassori, M. B. (2004). Sexualidade na adolescência: um estudo sobre jovens homens. Interaçôes, 9 (18), 109-126, jul-dez.

Torello, G. (2000). O psiquiatra na Internet: um paradoxo?. Psiquiatria na prática médica. Botucatu, 33 (2). Disponível em <www.unifesp.br/dpsiq/ polbr/ppm/especial02.htm>. (Acesso em 16 jul. 2009).

Torossian, S. D. (2007). Trajetos adolescentes na construção de toxicomanias. Psicologia em Revista. 13 (1), 123-136.

Winnicott, D. W. (1935). A defesa maníaca. In: Winnicott, D. W. Textos selecionados: da pediatria à psicanálise. (p. 247-267). Tradução Jane Russo. (2. ed.). Rio de Janeiro: F. Alves.

Winnicott, D. W. (1941). A observação de bebês em uma situação estabelecida. In: Winnicott, D. W. Textos selecionados: da Pediatria à Psicanálise. (pp. 139-164). Tradução Jane Russo. (2. ed.). Rio de Janeiro: Francisco Alves.

Winnicott, D. W. (1962a/1983). A integração do ego no desenvolvimento da criança. In: Winnicott, D. W. O ambiente e os processos de maturação: estudos sobre a teoria do desenvolvimento emocional. (pp. 55-61). Tradução Irineo Constantino Schuch Ortiz. Porto Alegre: Artes Médicas.

Winnicott, D. W. (1967a/1975). A localização da experiência cultural. In: Winnicott, D. W. O brincar e a realidade. (pp. 133-143). Tradução José Octávio de Aguiar Abreu e Vanede Nobre. Rio de Janeiro: Imago.

Winnicott, D. W. (1967b/1999). O conceito de indivíduo saudável. In: Winnicott, D. W. Tudo começa em casa. (pp. 3-22). Tradução de Paulo Sandler. São Paulo: Martins Fontes.

Winnicott, D. W. (1968a/1975). Conceitos contemporâneos de desenvolvimento adolescente e suas implicações para a educação superior. In: Winnicott, D. W. O brincar e a realidade. (pp. 187-202). Tradução José Octávio de Aguiar Abreu e Vanede Nobre. Rio de Janeiro: Imago.

Winnicott, D. W. (1968b/1999). A imaturidade do adolescente. In: Winnicott, D. W. Tudo começa em casa. (pp. 145-163). Tradução de Paulo Sandler. São Paulo: Martins Fontes.

Winnicott, D. W. (1968c). A comunicação entre o bebê e a mãe e entre a mãe e o bebê: convergências e divergências. In: Winnicott, D. W. Os 
bebês e suas mães. (pp. 79-92). Tradução Jefferson Luiz Camargo. São Paulo: Martins Fontes, 1994.

Winnicott, D. W. (1975). O brincar e a realidade. Tradução José Octávio de Aguiar Abreu e Vanede Nobre. Rio de Janeiro: Imago.

Winnicott, D. W. (1979/1983). O ambiente e os processos de maturação: estudos sobre a teoria do desenvolvimento emocional. Tradução Irineo Constantino Schuch Ortiz. Porto Alegre: Artes Médicas.

Winnicott, D. W. (1987/2002). O bebê e suas mães. São Paulo: Martins fontes.

Winnicott, D. W. (1993). A família e o desenvolvimento individual. Tradução de Marcelo Brandão Cipolla. São Paulo: Martins Fontes.

Winnicott, D. W. (1999). Tudo comę̧a em casa. Tradução de Paulo Sandler. São Paulo: Martins Fontes. 